\title{
Futbolda Yetenek Seçiminin Analitik Hiyerarşi Süreci ve TOPSIS Yöntemi Aracılığıyla Değerlendirilmesi
}

\author{
Serkan ESEN ${ }^{1} \quad$ Tuna USLU ${ }^{2}$
}

\begin{abstract}
Öz
Sporda ideal başarının elde edilebilmesi için, spora yönelik yeteneğin erken yaşta keşfedilmesi ve çocuğun yeteneğine uygun branşlara yönlendirilmesi gerekmektedir. Sporda mükemmellik arayışı yetenek tespiti, yeteneğin tanımlanması, seçimi ve geliştirilmesi olmak üzere dört aşamada tanımlanmaktadır. Ancak futbolda antrenörlerin daha iyi seçim yapmalarına destek olmak amacıyla çok kriterli karar verme yöntemlerinden yararlanılabilir. Bu amaçla çok kriterli karar verme yöntemlerinin futbolda yetenek seçimi için nasıl kullanılabileceğini sınamak üzere yaş ortalamas $9,64 \pm 0,37$ olan 20 erkek ilkokul öğrencisinin motorik beceri ölçüm değerleri Analitik Hiyerarşi Süreci ve Technique for Order Preference by Similarity to Ideal Solution (TOPSIS) yöntemleri aracılığı ile değerlendirilmiştir. İlgili alan yazın incelenerek kritik göstergeler belirlenmiş, futbol uzmanlarından görüş alınarak kriterler ve karar hiyerarşisi oluşturulmuştur. Analizde öncelikle futbola özgü kriterlerin (denge, reaksiyon, çabukluk, sıçrama, dayanıklılık ve esneklik) ağırlıklarının belirlenmesi için Analitik Hiyerarşi Süreci yöntemi kullanılmış, sporcuların sıralamasının yapılması için de Technique for Order Preference by Similarity to Ideal Solution yönteminden yararlanılmıştır. Çalışma sonucunda ortaya çıkan sıralama incelendiğinde kriter ağılıklarının sıralamadaki önemi ve nitel değerlendirmenin sonucu nasıl etkilediği gösterilmiştir. İleride yapılacak çalışmalarda futbol branşı için hesaplanan alana özgü ağırlıkların haricinde, diğer branşlara yönelik benzer şekilde uzmanlar yardımıla ağırlıkların hesaplanması, yetenek seçiminde hesaplamalı bir yöntem için de temel oluşturacaktır
\end{abstract}

Anahtar Kelimeler: Yetenek seçimi, Analitik Hiyerarşi Süreci, TOPSIS

\section{Evaluation of The Selection of Talents in Football Through the Analytical Hierarchy Process and TOPSIS Method}

\begin{abstract}
In order to achieve ideal success in sports, science for sports should be directed to other appropriate branches. The pursuit of excellence in sports is defined in four stages of talent determination, definition and selection of training. However, multi-criteria decision-making method can be used to support coaches to make better choices in football. For this purpose, in order to test how multi-criteria decision making methods can be used for talent selection in football, the motor skills measurement values of 20 male primary school students with an average age of $9.64 \pm 0.37$ are Analytical Hierarchy Process (AHP) and Technique for Order Preference by Similarity to Ideal Solution (TOPSIS) It was evaluated through methods.Critical analyzes, criteria expressing opinion from football experts and decision hierarchy were formed by researching the relevant field. In the analysis, firstly, Analytical Hierarchy Process method was used for the reason of the weight of footballspecific criteria (balance, reaction, quickness, jump, endurance and flexibility), and the Technique Similarity with the Ideal Solution Method was used for the construction of athletes. The study turned out to be the protagonist of the importance of criteria in ranking when examining the ranking and how qualitative evaluation affects the outcome. In the future studies, apart from the emphasis on the area calculated for the football branch, communication with experts for other branches will also be the basis for a computational method in talent selection.
\end{abstract}

\footnotetext{
${ }^{1}$ Sorumlu Yazar: Fenerbahçe Üniversitesi, serkan.esen@ gedik.edu.tr, İstanbul-Türkiye, https://orcid.org/0000-00019839-0390

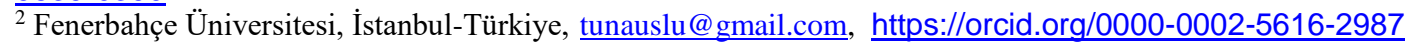


Keywords: Talent selection, Analytical Hierarchy Process, TOPSIS

\section{GíRiș}

Spor, uluslararası arenada ülkelerin prestij için yarıştığı ve başarılı olmak için çaba gösterdiği bir platformdur. $\mathrm{Bu}$ başarının sağlanabilmesi için de yetenekli sporculara ihtiyaç duyulmaktadır. Optimum başarının elde edilebilmesi için spordaki yeteneğin erken yaşta keşfedilmesi (Güçlüöver ve ark., 2019) ve yeteneğine en uygun branşa yönlendirilmesi gerekmektedir. Bazı çalışmalar erken yetenek seçiminin yetersiz olduğunu söylese de (Vaeyens, Lenoir, Williams, \& Philippaerts, 2008) birçok spor dalında ilerlemenin yolu olarak bu gösterilmektedir (Holtey ve Özer, 2019; Tutkun ve ark., 2006). Yeteneğin keşfinde ise branşa özgü fiziksel özelliklerin ön planda olması oldukça önemlidir (Ayan ve Mülazimoğlu, 2009) ve erken yaşlarda bu fiziksel özelliklerin ölçülmesi gerekmektedir (Mengütay, 1999).

Bilim insanları sporda mükemmellik arayışı sürecinde yetenek tespiti, tanımlanması, seçimi ve geliştirilmesi basamaklarını dört aşama şeklinde tanımlamışlardır. Bu nedenle, profesyonel futbol kulüplerinin teknik kadrosu, belirli antrenman programlarından faydalanabilecek ve kulüpte potansiyel olarak başarılı olabilecek oyuncuları keşfetmek için farklı programlar geliştirmektedir (Gil ve diğerleri, 2014).

Erken yaşta yeteneğin belirgin olamayacağından da bahseden bilim insanları gelecekte belli bir branşta başarılı olma ihtimali az olan insanları ayırt etmeye yardımcı olabileceğini düşünmektedirler (Howe ve ark., 1998).

Yetenek seçiminde iki farklı yöntemden bahsedilmektedir. Doğal seçim, sporcunun doğal olarak ilerleyiş ve geliş̧imini öngörür ve sporcu bir branşta başarılı olursa bu başarı tesadüf ile açılanabilir. Bilimsel seçim ise, kimin hangi spor dalında en iyi performans1 gösterebileceğini işaret eder ve bu şekilde seçilen sporcular kısa sürede performanslarını üst seviyelere taşır (Köktaş, 2013).

Yetenek seçimi gibi, farklı boyutları olan karmaşı (kompleks) sorunların çözümlenmesinde, insanların daha iyi seçim yapmalarına destek olmak amacıyla, bir dizi rassal alternatif içinden yalın ve belli kıstaslara bağlı optimum bir çözüm alternatifleri sıralaması ve önerisi sunmak için çok kriterli karar verme yöntemleri geliştirilmiştir (Lin vd., 2013). Karmaşık bir sorun, verimlilik, performans ve güvenilirlik gibi esasen ölçülemez, ancak çelişkili kriter ve hedeflerden oluşmakta şeklinde tanımlanmaktadır (Achillas, Moussiopoulos, Karagiannidis, Banias ve Perkoulidis, 2013). Coombs (1964) kriterlerin oluşturduğu ideal noktadan seçilebilecek alternatifler uzaklaştıkça, bu seçeneklerin karar alıcıya olan faydasının azaldığını belirtmektedir. Ancak kriterlerin çeliştiği problemlerde karar alma süreci karmaşıklaşmaktadır. Çok kriterli ve kriterlerin birbirleriyle çeliştiği durumlarda çok kriterli karar verme tekniklerine başvurulmaktadır (Harker ve Vargas, 1987).

Literatürde çok kriterli karar verme yöntemine yönelik yapılan bazı çalışmalar A takım seviyesine odaklanmış ve futbol alanında uzman kişilerin görüşleri (nitel) dahil edilmeden tasarlanmıștır (Sathya ve Jamal, 2009, Kasap ve Kasap, 2005, Qader ve diğerleri, 2017). Bu bağlamda çalışmamız, futbol alanında uzman kişilerin kriterleri (motorik özellikler) nitel bir şekilde değerlendirmesiyle tasarlanmış ve literatürdeki çalışmalara nazaran farklı bir bakış açısı sunmaktadır.

$\mathrm{Bu}$ çalışmanın amacı, çok kritere bağlı futbolda yetenek seçimi için Analitik Hiyerarşi Süreci (AHP) ve TOPSIS yöntemlerini birlikte kullanarak entegre bir karar verme yöntemini sınamaktır.

\section{YÖNTEM}

\section{Çalışma Grubu}

Etik kurul raporu alınmış olan bu çalışma, Türkiye Futbol Federasyonu (TFF) ve Üniversite iş birliği ile yürütülen "TFF Üniversite Çocuk Futbolu Eğitim Projesi" kapsamında tasarlanmış ve ilkokul çocuklarına yönelik düzenlenen futbol faaliyetleri sonrasında rastgele seçilen bir okulun 3. sınıfindaki yaş ortalamas $9,64 \pm 0,37$ olan 20 erkek ilkokul öğrencisine uygulanmıştır. Yapılan ölçümler, ilgili literatür taranarak (Aktuğ, Rüçhan ve Çelenk, 2019, Kurban, 2008) ve uzman görüşleri alınarak seçilmiş, okul idaresi, öğretmen ve 
ailelerden izin alınarak okul bahçesinde gerçekleştirilmiştir.

\section{İslem}

Veri seti olarak denge, reaksiyon, çabukluk, sıçrama, dayanıklılık ve esneklik ölçümlerinin nicel test sonuçlarından oluşan bir örneklem kullanılmıştır.

Denge (Flamingo denge testi): Araştırma grubunun statik dengelerinin belirlenmesi amaciyla Flamingo Denge Testi kullanılmıştır. Araştırma grubu; $50 \mathrm{~cm}$. uzunluğunda, $4 \mathrm{~cm}$. yüksekliğinde ve $3 \mathrm{~cm}$. genişliğinde tahta bir denge aletinin üzerine dominant ayağı ile çıkarak dengede durur. Diğer ayağını dizinden büküp, kalçasına doğru çekerek, aynı taraftaki eli ile tutar. Bu aşamada süre başlatılır ve 1 dakika boyunca bu şekilde dengede kalmaya çalışılır. Denge bozulursa süre durdurulur. Araştırma grubu, denge aletine çıkarak dengesini tekrar sağladığında, süre kaldığı yerden devam eder. Süre tamamlandığında, araştırma grubunun her denge sağlama girişimi sayılır ve bu sayı test bitiminde puan olarak kaydedilir.

Reaksiyon (Görsel): Görsel reaksiyon ölçümleri Newtest 1000 aleti ile yeterli 1 şı alabilen ortamda gerçekleştirilmiş ve ölçüm sonuç kâğıtlarına kaydedilmiştir. Her katılımcı ölçüme 3 deneme ve 5 ölçüm ile katılmıştır ve 5 ölçümün ortalaması saniye cinsinden kaydedilmiştir.

Çabukluk: Çabukluk beceri özelliğinin belirlenmesi aşamasında $5 \times 10$ metrelik bir alan ve belirli noktalara huniler koyularak ölçüm alınmıştır. Veriler saniye cinsinden not edilmiştir.

Sıçrama: Araştırma grubunun sıçrama becerisini ölçmek için katılımcılar tek ayak üzerinde üç kez arka arkaya ve aralarda bekleme yapmadan siçrar ve en uzak mesafeye ulaşmaya çalışır. Ulaştığı noktada da 2 sn. dengede kalması beklenir.

Dayanıklılık: Dayanıklılık testi için katılımcılar minderin üzerinde bacakları dizlerden bükülü vaziyette ve topuklar kalçadan $30 \mathrm{~cm}$ uzaklıkta olacak şekilde elleri başının iki yanında, kolları yanda sırtüstü uzanarak standart mekik pozisyonu alır ve ölçüm başlatılır. 30 saniye süresince nizami çektiği mekikler sayılarak ulaştığı sayı puan olarak kaydedilir.

Esneklik: Araştırma grubunun esnekliklerinin belirlenmesi amaciyla otur-eriş testi kullanılmıştır. Araştırma grubu yere oturarak bacaklarını uzatır ve ayakkabısız bir şekilde ayak tabanlarını sehpaya dayar. Sonra gövdesinden ve dizlerini bükmeden, sehpanın üzerinde ileriye doğru, mümkün olduğunca ileriye uzanır. Parmaklarının uzandığ en uç nokta santimetre cinsinden ölçülür. Üç dene sonunda en iyi derece kaydedilir.

\section{Verilerin Analizi}

Ölçümlerde elde edilen verilerin kriter ağırlıklarının hesaplanması için, Analitik Hiyerarşi Süreci (AHP) tekniğinden yararlanılmıştır. Elde edilen kriter ağırlıkları çok kriterli karar verme yöntemlerinden biri olan TOPSIS yöntemi ile değerlendirilmiş ve öğrencilerin performanslarına göre sıralaması oluşturulmuştur. AHP sürecinde Wharton'un rastgele değer indeksi kullanılmıştır (Yıldırım ve Önder, 2015).

\section{Çok Kriterli Karar Verme}

Çok kriterli ve bütünleşik karar verme yöntemlerinin, veriden belirli kriterlere göre seçim yapılması gereken durumlarda sıklıkla kullanıldığı (Kousalya, Ravindranath, Vzayakumar, 2006), hatta kullanım oranının tek yöntemle karar vermeye yakın olduğu görülmektedir (Ho, Xu ve Dey, 2010). AHP diğer yöntemlerle birlikte en sik kullanılan yöntem olarak karşımıza çıkmaktadır. $\mathrm{Bu}$ yöntemin karar verme sürecinde tercih edilmesinin nedeni, tekniğin nitel ve nicel birden fazla kıstasın karşılaştırmalı olarak birlikte değerlendirmesine olanak sağlıyor olmasıdır. Literatürde AHP ile TOPSIS yönteminin de bir arada kullanıldığı görülmektedir. Örneğin; havaalanlarındaki hizmet kalitesinin değerlendirilmesinde Tsaur, Chang ve Yen (2002), müşteri odaklı ürün tasarıminda Lin, Wang, Chen ve Chang (2008), tekstil endüstrisinde en iyi bakım yönteminin belirlenmesinde Shyjith, Ilangkumaran ve Kumanan (2008) AHP ve TOPSIS yöntemlerini birlikte kullanmışlardır. 


\section{Analitik Hiyerarşi Süreci}

Analitik Hiyerarşi Süreci (AHP), Thomas Saaty tarafından 1970'li yıllarda geliştirilmiş, karar vericiler tarafından çok kriterli ortamda rekabet eden alternatifler arasında seçim yapmayı kolaylaştıran bir yöntemdir (Forman ve Gass, 2001; Karaatlı, Ömürbek ve Köse, 2014). Seçim yapma işlemi öncesinde alternatiflerin sıralanması konusunda sayısal skor geliştirir (Ünal, 2011) ve karmaşık olan bir durumu basite indirger (Chen, 2006). Böylelikle geleneksel karar verme yöntemleriyle yapılandırılması zor ya da imkansiz olan problemler AHP ile daha kolay bir hale dönüşür (Jabri, 1990). AHP, çok kaynaktan beslenen bir problemin, süreç olarak ana hedefinin, hedefin alt kriterlerinin ve alternatiflerin hiyerarşik bir yapıda çözümlenmesini sağlamak için geliştirilen bir karar verme tekniğidir (Wind ve Saaty, 1980, Saaty, 2008). Bu süreç problemin ayrıştırılması, önceliklerin belirlenmesi, sentezleme ve duyarlılık analizi şeklinde dört basamaktan oluşmaktadır (Forman ve Selly, 2001).

AHP, hem nicel hem de nitel faktörlerden faydalanarak karar vermeyi kolaylaştıran güçlü bir yöntemdir (Saaty, 1994). Modern futbolun hizla değişen dinamiklerine en uygun oyuncuyu keșfetmek için alanda uzman kişilerin kriterleri kıyaslayarak sürece dahil olmas1, futbola en uygun yetenekli sporcuların keşfedilmesinde önemli bir rol oynayacaktır. AHP'nin karar verme aşamasında tercih edilme nedenlerinin de başında bu gelmektedir.

Tablo 1: AHP İkili Karşılaştırmalar Ölçeği

\begin{tabular}{|c|c|c|}
\hline Derecesi & Değer Tanımları & Açıklaması \\
\hline 1 & Eşit önemli & Her iki faaliyet amaca eşit katkıda bulunur. \\
\hline 3 & Orta Önemli (Az Üstünlük) & $\begin{array}{l}\text { Tecrübe ve değerlendirmeler sonucunda bir faaliyet diğerine } \\
\text { göre biraz daha tercih edilir. }\end{array}$ \\
\hline 5 & $\begin{array}{l}\text { Güçlü Önemde (Fazla } \\
\text { Üstünlük) }\end{array}$ & $\begin{array}{l}\text { Tecrübe ve değerlendirmeler sonucunda bir faaliyet diğerine } \\
\text { göre çok daha tercih edilir. }\end{array}$ \\
\hline 7 & $\begin{array}{l}\text { Çok Güçlü Önemde (Çok } \\
\text { Üstünlük) }\end{array}$ & Bir faaliyet diğerine göre çok güçlü şekilde tercih edilir. \\
\hline 9 & $\begin{array}{l}\text { Son Derece Önemli (Kesin } \\
\text { Üstünlük) }\end{array}$ & $\begin{array}{l}\text { Bir faaliyet diğerine göre mümkün olan en yüksek derecede } \\
\text { tercih edilir. }\end{array}$ \\
\hline $2,4,6,8$ & $\begin{array}{l}\text { Ara Değerler (Uzlaşma } \\
\text { Değerleri) }\end{array}$ & $\begin{array}{l}\text { Bir değerlendirmeyi yapmakta sözler yetersiz kalıyorsa, sayısal } \\
\text { değerlerin ortasındaki bir değer verilir. }\end{array}$ \\
\hline
\end{tabular}

\section{TOPSIS Yöntemi}

TOPSIS (Technique for Order Preference by Similarity to Ideal Solution), nitel bir değerlendirme yapılmaksızın doğrudan eldeki veri üzerinden, çözüm seçeneğinin ideal (en iyi) çözüme en yakın mesafe ve negatif ideal çözüme en uzak olan mesafeden yola çıkarak bir çözüm önerisi sunacak şekilde Hwang ve Yoon (1981) tarafından ortaya atılmış sağlam ve güvenilir bir karar verme tekniğidir (Yoon, 1987; Lai, Liu ve Hwang, 1994; Opricovic ve Tzeng, 2004; Wei, 2010; Monjezi, Dehghani,
Singh, Sayadi ve Gholinejad, 2010). Hwang ve Yoon (1981), çözüm noktasının pozitif ideal çözüme en yakın ve negatif ideal çözüme ise en uzak mesafede olacağ 1 varsayımına dayanarak bu yöntemi geliştirmişlerdir. Yöntem, pozitif ideal çözüme en yakın olan alternatifin, aynı zamanda negatif ideal çözüme de en uzak olacağını varsayar (Chen, 2000). Yöntem, ideal çözüme en yakın ve negatif ideal çözüme en uzak Öklid mesafesinde bir çözüm 
tespit eder, ancak mesafelerin göreceli önemini dikkate almaz (Cristóbal, 2012), uzaklıkların tekdüze bir şekilde artan veya azalan bir fayda eğilimine sahip olduğu varsayılır. Bu yöntemde ilk olarak seçenekler yukarıdan aşağıya sıralanarak, her bir alternatifin karşısına o alternatifin ilgili kritere göre özelliklerinin yazıldığı bir karar matrisi kullanılarak sıralama işlemi yapılmaktadır (Timor, 2011)

TOPSIS, problemin, uzman görüşü alınarak kriterlerin ve alternatiflerin tanımlanması, kriterlerin ağırlıklarının belirlenmesi, karar matrisinin, normalize etme formülü ile hesaplanmış standart karar ve ağırlıklı standart karar matrisinin oluşturulması, pozitif ideal ve negatif ideal çözümlerin belirlenmesi, Öklid mesafesine göre ayırım ölçülerinin hesaplanması ve ideal çözüme göreli yakınlığın tespit edilmesi ve alternatiflerin sıralanması olmak üzere 11 aşamayla çözümleme yapar.

\section{BULGULAR}

Amacin "en yetenekli sporcu"yu belirlemenin olduğu bir problemin kriterleri bu uygulama için aşağıda gösterilmiştir:

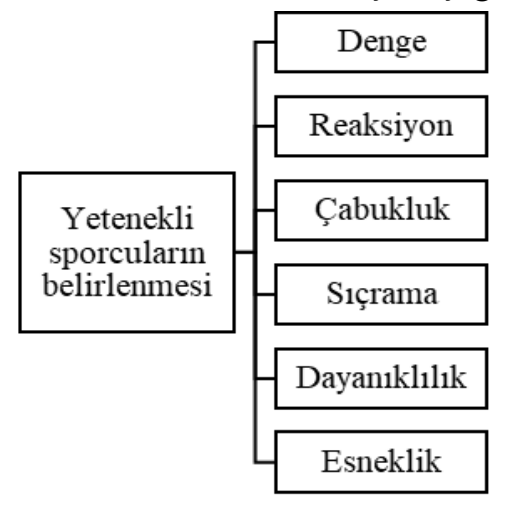

Şekil 1. Yetenek Belirleme Hiyerarşisi

Alanda uzman 10 kişi (altyapı antrenörleri ve futbol alanında çalışmalar yürüten akademisyenler) değerlendirme kriterlerini ikili karşılaştırma matrisine göre puanlandırmış ve aritmetik ortalamaları hesaplanarak aşağıdaki tabloda gösterilmiştir:

Tablo 2. İkili Karşılaştırma Matrisi

\begin{tabular}{|c|c|c|c|c|c|c|}
\hline & Denge & Reaksiyon & Çabukluk & Siçrama & Dayanıklılık & Esneklik \\
\hline Denge & 1,00 & 1,19 & 1,94 & 2,31 & 3,45 & 2,67 \\
\hline Reaksiyon & 0,84 & 1,00 & 2,33 & 2,89 & 3,45 & 3,67 \\
\hline Çabukluk & 0,51 & 0,43 & 1,00 & 2,00 & 4,17 & 1,89 \\
\hline Siçrama & 0,43 & 0,35 & 0,50 & 1,00 & 3,42 & 2,72 \\
\hline Dayanıklılık & 0,29 & 0,29 & 0,24 & 0,29 & 1,00 & 1,15 \\
\hline Esneklik & 0,38 & 0,27 & 0,53 & 0,37 & 0,87 & 1,00 \\
\hline \multicolumn{4}{|c|}{$\begin{array}{l}\text { Uzman görüşlerinden elde edilen ikili } \\
\text { karşılaştırma matrisinin tutarlılık oranı (T.O.) } \\
0,04 \text { olarak bulunmuş, bu değer AHP } \\
\text { modellerinde kabul seviyesi olan üst sınır } \\
\text { 0,1'den küçük olması sebebiyle matristen elde } \\
\text { edilen sonuçların tutarlı olduğuna karar }\end{array}$} & \multicolumn{3}{|c|}{$\begin{array}{l}\text { verilmiştir. İkili karşılaştırma matrisindeki he } \\
\text { bir değer, bulunduğu sütunun toplamına } \\
\text { bölünerek normalize edilmiş ikil } \\
\text { karşılaştırma matrisi oluşturulmuştur } \\
\text { Normalize edilmiş ikili karşılaştırma veriler } \\
\text { excel programı aracılığı ile hesaplanarak } \\
\text { genel ağırlıkları bulundu (Tablo 3). }\end{array}$} \\
\hline
\end{tabular}


Esen, S., Uslu, T. / Futbolda Yetenek Seçiminin Analitik Hiyerarşi Süreci ve TOPSIS Yöntemi Aracılığıyla Değerlendirilmesi

Tablo 3. Normalize Edilmiş İkili Karşılaştırma Matrisi

\begin{tabular}{lllllll}
\hline & Denge & Reaksiyon & Çabukluk & Sıçrama & Dayanıklılık & Esneklik \\
Denge & 0,29 & 0,34 & 0,30 & 0,26 & 0,21 & 0,20 \\
Reaksiyon & 0,24 & 0,28 & 0,36 & 0,33 & 0,21 & 0,28 \\
Çabukluk & 0,15 & 0,12 & 0,15 & 0,23 & 0,25 & 0,14 \\
Siçrama & 0,13 & 0,10 & 0,08 & 0,11 & 0,21 & 0,21 \\
Dayanıklılık & 0,08 & 0,08 & 0,04 & 0,03 & 0,06 & 0,09 \\
Esneklik & 0,11 & 0,08 & 0,08 & 0,04 & 0,05 & 0,08 \\
\hline
\end{tabular}

Tablo 4. Kriter Ağırlıkları

\begin{tabular}{|c|c|c|c|c|c|c|}
\hline \multicolumn{4}{|c|}{ Kriterler } & \multicolumn{3}{|c|}{ Ağırlıklar } \\
\hline \multicolumn{4}{|c|}{ Reaksiyon } & \multicolumn{3}{|c|}{0,28} \\
\hline \multicolumn{4}{|c|}{ Denge } & \multicolumn{3}{|c|}{0,27} \\
\hline \multicolumn{4}{|c|}{ Çabukluk } & \multicolumn{3}{|c|}{0,17} \\
\hline \multicolumn{4}{|c|}{ Siçrama } & \multicolumn{3}{|c|}{0,14} \\
\hline \multicolumn{4}{|c|}{ Esneklik } & \multicolumn{3}{|c|}{0,07} \\
\hline \multicolumn{4}{|c|}{ Dayanıklılık } & \multicolumn{3}{|c|}{0,06} \\
\hline \multicolumn{4}{|c|}{$\begin{array}{l}\text { Tablo incelendiğinde yetenek seçiminde } \\
\text { kullanılan kriterlerden reaksiyon } 0,28 \text { değeri } \\
\text { ile ilk sıradadır. İkinci sırada denge }(0,27) \text {, } \\
\text { üçüncü sırada çabukluk }(0,17) \text { ve sirasıyla } \\
\text { sıçrama }(0,14) \text {, esneklik }(0,07) \text { ve dayanıkl1lık } \\
(0,06) \text { kriterleri gelmektedir. Bu değerlere } \\
\text { bakıldığında çalışmaya katılan yaş grubunun }\end{array}$} & \multicolumn{3}{|c|}{$\begin{array}{l}(\bar{x}=9,64) \text { yetenek seçiminde reaksiyon ve } \\
\text { denge kriterleri diğer kriterlere göre daha } \\
\text { fazla önem teşkil etmektedir. Uygulamada } \\
\text { kullanilan karar matrisi aşağidaki tabloda } \\
\text { gösterilmiştir. Karar matrisine göre toplamda } \\
\text { 20 sporcunun } 6 \text { kritere ait performans verileri } \\
\text { görülmektedir (Tablo 5). }\end{array}$} \\
\hline \multicolumn{7}{|c|}{ Tablo 5. Karar Matrisi } \\
\hline Sporcu & Denge & Reaksiyon (sn) & Çabukluk (sn) & Siçrama (cm) & Dayanıklılık & Esneklik (cm) \\
\hline A & 5 & 0,270 & 10,38 & 525 & 31 & 20 \\
\hline $\mathrm{B}$ & 14 & 0,270 & 11,28 & 400 & 11 & 24 \\
\hline $\mathrm{C}$ & 6 & 0,380 & 10,94 & 425 & 9 & 27 \\
\hline D & 3 & 0,201 & 10,44 & 425 & 16 & 29 \\
\hline $\mathrm{E}$ & 12 & 0,390 & 10,63 & 425 & 17 & 22 \\
\hline $\mathrm{F}$ & 6 & 0,285 & 11,4 & 375 & 16 & 27 \\
\hline G & 3 & 0,210 & 10,16 & 450 & 21 & 25 \\
\hline $\mathrm{H}$ & 9 & 0,200 & 10,32 & 475 & 41 & 23 \\
\hline I & 6 & 0,210 & 10,44 & 450 & 28 & 22 \\
\hline $\mathrm{J}$ & 6 & 0,211 & 10,53 & 475 & 23 & 34 \\
\hline $\mathrm{K}$ & 10 & 0,271 & 11,00 & 380 & 32 & 23 \\
\hline $\mathrm{L}$ & 15 & 0,220 & 10,59 & 405 & 18 & 24 \\
\hline M & 8 & 0,270 & 11,25 & 415 & 23 & 28 \\
\hline $\mathrm{N}$ & 8 & 0,211 & 11,53 & 400 & 26 & 25 \\
\hline $\mathrm{O}$ & 15 & 0,264 & 10,56 & 350 & 30 & 18,5 \\
\hline $\mathrm{P}$ & 15 & 0,220 & 12,53 & 315 & 17 & 23,5 \\
\hline $\mathrm{R}$ & 15 & 0,280 & 11,65 & 360 & 11 & 21,5 \\
\hline $\mathrm{S}$ & 11 & 0,220 & 12 & 310 & 24 & 25 \\
\hline $\mathrm{T}$ & 9 & 0,290 & 11,10 & 360 & 40 & 30 \\
\hline $\mathrm{U}$ & 13 & 0,181 & 14,25 & 305 & 17 & 15,5 \\
\hline
\end{tabular}


Esen, S., Uslu, T. / Futbolda Yetenek Seçiminin Analitik Hiyerarşi Süreci ve TOPSIS Yöntemi Aracılığıyla Değerlendirilmesi

Tablo 6. Normalize Edilmiş Karar Matrisi

\begin{tabular}{ccccccc}
\hline Sporcu & Denge & Reaksiyon & Çabukluk & Siçrama & Dayanıllılı & Esneklik \\
\hline A & 0,109 & 0,233 & 0,207 & 0,290 & 0,286 & 0,181 \\
B & 0,305 & 0,233 & 0,225 & 0,221 & 0,102 & 0,217 \\
C & 0,131 & 0,329 & 0,219 & 0,234 & 0,083 & 0,245 \\
D & 0,065 & 0,174 & 0,209 & 0,234 & 0,148 & 0,263 \\
E & 0,261 & 0,337 & 0,212 & 0,234 & 0,157 & 0,199 \\
F & 0,131 & 0,246 & 0,228 & 0,207 & 0,148 & 0,245 \\
G & 0,065 & 0,182 & 0,203 & 0,248 & 0,194 & 0,226 \\
H & 0,196 & 0,173 & 0,206 & 0,262 & 0,379 & 0,208 \\
I & 0,131 & 0,182 & 0,209 & 0,248 & 0,259 & 0,199 \\
J & 0,131 & 0,182 & 0,210 & 0,262 & 0,212 & 0,308 \\
K & 0,218 & 0,234 & 0,220 & 0,210 & 0,295 & 0,208 \\
L & 0,327 & 0,190 & 0,212 & 0,223 & 0,166 & 0,217 \\
M & 0,174 & 0,233 & 0,225 & 0,229 & 0,212 & 0,254 \\
N & 0,174 & 0,182 & 0,230 & 0,221 & 0,240 & 0,226 \\
O & 0,327 & 0,228 & 0,211 & 0,193 & 0,277 & 0,168 \\
P & 0,327 & 0,190 & 0,250 & 0,174 & 0,157 & 0,213 \\
R & 0,327 & 0,242 & 0,233 & 0,199 & 0,102 & 0,195 \\
S & 0,240 & 0,190 & 0,240 & 0,171 & 0,222 & 0,226 \\
T & 0,196 & 0,251 & 0,222 & 0,199 & 0,369 & 0,272 \\
U & 0,283 & 0,156 & 0,285 & 0,168 & 0,157 & 0,140 \\
\hline
\end{tabular}

İkili karşılaştırma matrisinde olduğu gibi karar matrisinin de normalizasyon işlemi yapılmış (Tablo 6) ve AHP tekniği ile elde edilen ağırlık katsayıları ile çarpılarak ağırlıklandırılmış karar matrisi aşağıdaki gibi (Tablo 7) hesaplanmıştır:

Tablo 7. Ağırlıklandırılmış Karar Matrisi

\begin{tabular}{ccccccc}
\hline Sporcu & Denge & Reaksiyon & Çabukluk & Sıçrama & Dayanıklılı & Esneklik \\
A & 0,029 & 0,066 & 0,036 & 0,040 & 0,018 & 0,013 \\
B & 0,081 & 0,066 & 0,039 & 0,031 & 0,007 & 0,016 \\
C & 0,035 & 0,093 & 0,038 & 0,032 & 0,005 & 0,018 \\
D & 0,017 & 0,049 & 0,036 & 0,032 & 0,009 & 0,019 \\
E & 0,070 & 0,096 & 0,037 & 0,032 & 0,010 & 0,015 \\
F & 0,035 & 0,070 & 0,040 & 0,029 & 0,009 & 0,018 \\
G & 0,017 & 0,051 & 0,035 & 0,034 & 0,012 & 0,017 \\
H & 0,052 & 0,049 & 0,036 & 0,036 & 0,024 & 0,015 \\
I & 0,035 & 0,051 & 0,036 & 0,034 & 0,017 & 0,015 \\
J & 0,035 & 0,052 & 0,037 & 0,036 & 0,014 & 0,022 \\
K & 0,058 & 0,066 & 0,038 & 0,029 & 0,019 & 0,015 \\
L & 0,087 & 0,054 & 0,037 & 0,031 & 0,011 & 0,016 \\
M & 0,046 & 0,066 & 0,039 & 0,032 & 0,014 & 0,019 \\
N & 0,046 & 0,052 & 0,040 & 0,031 & 0,015 & 0,017 \\
O & 0,087 & 0,065 & 0,037 & 0,027 & 0,018 & 0,012 \\
P & 0,087 & 0,054 & 0,044 & 0,024 & 0,010 & 0,016 \\
R & 0,087 & 0,069 & 0,041 & 0,027 & 0,007 & 0,014 \\
S & 0,064 & 0,054 & 0,042 & 0,024 & 0,014 & 0,017 \\
T & 0,052 & 0,071 & 0,039 & 0,027 & 0,024 & 0,020 \\
U & 0,075 & 0,044 & 0,050 & 0,023 & 0,010 & 0,010 \\
\hline
\end{tabular}

Ağırlıklı standart karar matrisindeki sütun değerlerinin en büyük (min) ve en küçükleri (max) belirlenmiştir (Tablo 8). Pozitif ideal uzaklık ve negatif ideal uzaklık tabloları aşağıdaki gibi oluşturulmuştur (Tablo 9 ve Tablo 10). 
Esen, S., Uslu, T. / Futbolda Yetenek Seçiminin Analitik Hiyerarşi Süreci ve TOPSIS Yöntemi Aracılığıyla Değerlendirilmesi

Tablo 8. Karar matrisi Min. ve Max. Değerleri

\begin{tabular}{ccccccc}
\hline Sporcu & Denge & Reaksiyon & Çabukluk & Sıçrama & Dayanıklılık & Esneklik \\
Max & 0,087 & 0,096 & 0,050 & 0,040 & 0,024 & 0,022 \\
Min & 0,017 & 0,044 & 0,035 & 0,023 & 0,005 & 0,010 \\
\hline
\end{tabular}

Tablo 9. Pozitif İdeal Uzaklık Değerleri

\begin{tabular}{ccccccccc}
\hline Sporcu & Denge & Reaksiyon & Çabukluk & Siçrama & Dayanıklılık & Esneklik & Toplam & Poz. İdeal U. \\
A & 0,0034 & 0,0009 & 0,0002 & 0,0000 & 0,0000 & 0,0001 & 0,0045 & 0,033 \\
B & 0,0000 & 0,0009 & 0,0001 & 0,0001 & 0,0003 & 0,0000 & 0,0015 & 0,068 \\
C & 0,0027 & 0,0000 & 0,0001 & 0,0001 & 0,0004 & 0,0000 & 0,0033 & 0,053 \\
D & 0,0049 & 0,0021 & 0,0002 & 0,0001 & 0,0002 & 0,0000 & 0,0075 & 0,014 \\
E & 0,0003 & 0,0000 & 0,0002 & 0,0001 & 0,0002 & 0,0001 & 0,0008 & 0,074 \\
F & 0,0027 & 0,0007 & 0,0001 & 0,0001 & 0,0002 & 0,0000 & 0,0039 & 0,033 \\
G & 0,0049 & 0,0019 & 0,0002 & 0,0000 & 0,0001 & 0,0000 & 0,0072 & 0,016 \\
H & 0,0012 & 0,0022 & 0,0002 & 0,0000 & 0,0000 & 0,0001 & 0,0036 & 0,042 \\
I & 0,0027 & 0,0019 & 0,0002 & 0,0000 & 0,0001 & 0,0001 & 0,0050 & 0,025 \\
J & 0,0027 & 0,0019 & 0,0002 & 0,0000 & 0,0001 & 0,0000 & 0,0050 & 0,027 \\
K & 0,0008 & 0,0009 & 0,0001 & 0,0001 & 0,0000 & 0,0001 & 0,0020 & 0,049 \\
L & 0,0000 & 0,0017 & 0,0002 & 0,0001 & 0,0002 & 0,0000 & 0,0022 & 0,071 \\
M & 0,0017 & 0,0009 & 0,0001 & 0,0001 & 0,0001 & 0,0000 & 0,0028 & 0,039 \\
N & 0,0017 & 0,0019 & 0,0001 & 0,0001 & 0,0001 & 0,0000 & 0,0039 & 0,033 \\
O & 0,0000 & 0,0010 & 0,0002 & 0,0002 & 0,0000 & 0,0001 & 0,0014 & 0,074 \\
P & 0,0000 & 0,0017 & 0,0000 & 0,0003 & 0,0002 & 0,0000 & 0,0023 & 0,071 \\
R & 0,0000 & 0,0007 & 0,0001 & 0,0002 & 0,0003 & 0,0001 & 0,0014 & 0,074 \\
S & 0,0005 & 0,0017 & 0,0001 & 0,0003 & 0,0001 & 0,0000 & 0,0027 & 0,049 \\
T & 0,0012 & 0,0006 & 0,0001 & 0,0002 & 0,0000 & 0,0000 & 0,0021 & 0,049 \\
U & 0,0001 & 0,0026 & 0,0000 & 0,0003 & 0,0002 & 0,0001 & 0,0034 & 0,060 \\
\hline
\end{tabular}

Tablo 10. Negatif İdeal Uzaklık Değerleri

\begin{tabular}{ccccccccc}
\hline Sporcu & Denge & Reaksiyon & Çabukluk & S1çrama & Dayanıkl1lık & Esneklik & Toplam & Neg. İdeal U. \\
A & 0,0001 & 0,0005 & 0,0000 & 0,0003 & 0,0002 & 0,0000 & 0,001 & 0,0674 \\
B & 0,0041 & 0,0005 & 0,0000 & 0,0001 & 0,0000 & 0,0000 & 0,005 & 0,0382 \\
C & 0,0003 & 0,0024 & 0,0000 & 0,0001 & 0,0000 & 0,0001 & 0,003 & 0,0575 \\
D & 0,0000 & 0,0000 & 0,0000 & 0,0001 & 0,0000 & 0,0001 & 0,000 & 0,0864 \\
E & 0,0027 & 0,0026 & 0,0000 & 0,0001 & 0,0000 & 0,0000 & 0,005 & 0,0280 \\
F & 0,0003 & 0,0006 & 0,0000 & 0,0000 & 0,0000 & 0,0001 & 0,001 & 0,0622 \\
G & 0,0000 & 0,0001 & 0,0000 & 0,0001 & 0,0001 & 0,0000 & 0,000 & 0,0849 \\
H & 0,0012 & 0,0000 & 0,0000 & 0,0002 & 0,0004 & 0,0000 & 0,002 & 0,0603 \\
I & 0,0003 & 0,0001 & 0,0000 & 0,0001 & 0,0001 & 0,0000 & 0,001 & 0,0708 \\
J & 0,0003 & 0,0001 & 0,0000 & 0,0002 & 0,0001 & 0,0001 & 0,001 & 0,0704 \\
K & 0,0017 & 0,0005 & 0,0000 & 0,0000 & 0,0002 & 0,0000 & 0,002 & 0,0450 \\
L & 0,0049 & 0,0001 & 0,0000 & 0,0001 & 0,0000 & 0,0000 & 0,005 & 0,0470 \\
M & 0,0008 & 0,0005 & 0,0000 & 0,0001 & 0,0001 & 0,0001 & 0,002 & 0,0532 \\
N & 0,0008 & 0,0001 & 0,0000 & 0,0001 & 0,0001 & 0,0000 & 0,001 & 0,0622 \\
O & 0,0049 & 0,0004 & 0,0000 & 0,0000 & 0,0002 & 0,0000 & 0,005 & 0,0380 \\
P & 0,0049 & 0,0001 & 0,0001 & 0,0000 & 0,0000 & 0,0000 & 0,005 & 0,0477 \\
R & 0,0049 & 0,0006 & 0,0000 & 0,0000 & 0,0000 & 0,0000 & 0,006 & 0,0368 \\
S & 0,0022 & 0,0001 & 0,0000 & 0,0000 & 0,0001 & 0,0000 & 0,002 & 0,0524 \\
T & 0,0012 & 0,0007 & 0,0000 & 0,0000 & 0,0003 & 0,0001 & 0,002 & 0,0458 \\
U & 0,0034 & 0,0000 & 0,0002 & 0,0000 & 0,0000 & 0,0000 & 0,004 & 0,0582 \\
\hline
\end{tabular}


Tablo 11. İdeal Çözüme Göreli Uzaklık Değerleri

\begin{tabular}{cccc}
\hline Sporcu & S+ & S- & C \\
A & 0,033 & 0,067 & 0,673 \\
B & 0,068 & 0,038 & 0,359 \\
C & 0,053 & 0,058 & 0,520 \\
D & 0,014 & 0,086 & 0,858 \\
E & 0,074 & 0,028 & 0,275 \\
F & 0,033 & 0,062 & 0,655 \\
G & 0,016 & 0,085 & 0,840 \\
H & 0,042 & 0,060 & 0,588 \\
I & 0,025 & 0,071 & 0,739 \\
J & 0,027 & 0,070 & 0,720 \\
K & 0,049 & 0,045 & 0,479 \\
L & 0,071 & 0,047 & 0,398 \\
M & 0,039 & 0,053 & 0,575 \\
N & 0,033 & 0,062 & 0,651 \\
O & 0,074 & 0,038 & 0,340 \\
P & 0,071 & 0,048 & 0,401 \\
R & 0,074 & 0,037 & 0,331 \\
S & 0,049 & 0,052 & 0,516 \\
T & 0,049 & 0,046 & 0,484 \\
U & 0,060 & 0,058 & 0,493 \\
\hline
\end{tabular}

Tablo 12. İdeal Çözüme Göreli Uzaklığa Göre Sıralanmış En İyi Beş Sporcunun Verileri

\begin{tabular}{cccccccc}
\hline $\begin{array}{c}\text { Ağrllklar } \\
\text { Sporcu }\end{array}$ & 0,27 & 0,28 & 0,17 & 0,14 & 0,06 & 0,07 & \\
Denge & Reaksiyon & Çabukluk & Siçrama & Dayanılılık & Esneklik & C \\
D & 3 & 0,201 & 10,44 & 425 & 16 & 29 & 0,85 \\
G & 3 & 0,210 & 10,16 & 450 & 21 & 25 & 0,83 \\
I & 6 & 0,210 & 10,44 & 450 & 28 & 22 & 0,73 \\
J & 6 & 0,211 & 10,53 & 475 & 23 & 34 & 0,72 \\
A & 5 & 0,270 & 10,38 & 525 & 31 & 20 & 0,67 \\
\hline
\end{tabular}

Pozitif ideal uzaklık ve negatif ideal uzaklığın hesaplanmasından sonra, ideal çözüme göreli yakınlığı hesaplanarak puanı en yüksek olan sporcular büyükten küçüğe sıralanır (Tablo

\section{TARTIŞMA ve SONUÇ}

Saha çalışmasında yaş ortalaması $9,64 \pm 0,37$ olan 20 erkek ilkokul öğrencisine denge, reaksiyon, çabukluk, sıçrama, dayanıklılık ve esneklik testleri uygulanmıştır.

$\mathrm{Bu}$ verilerle yapılan hesaplamalar sonucunda 20 sporcu içinde futbola fiziksel açıdan en
11). TOPSIS yöntemine göre yapılan hesaplamalar sonucunda 20 sporcu içinden en iyi 5 sporcunun siralamasi tablo 12'deki gibidir:

uygun 5 sporcu sirasiyla D, G, I, J ve A sporcuları olmuştur. Veriler incelendiğinde D ve $G$ sporcularının diğer oyunculardan daha iyi dengeye (ağırlık=0,27) sahip oldukları görülmektedir. D sporcusunun çabukluk, sıçrama ve dayanıklılık kriterlerinde $G$ sporcusundan daha kötü derecelere sahip 
olmasına karşın $\mathrm{G}$ sporcusunun üstünde yer almasının sebebi olarak 0,28 ağırlığa sahip reaksiyon kriterinin daha yüksek olmas1 gösterilebilir $(0,201<0,210)$.

A sporcusunun denge, çabukluk ve dayanıkl1lık kriterlerinin üstündeki iki sporcudan daha iyi olmasına rağmen 5 . sırada olması 0,28 ile en yüksek ağırlığa sahip reaksiyon kriterinin diğerlerine göre rakamsal olarak çok daha kötü olması şeklinde açıklanabilir $(0,270>0,211>0,210)$.

Yukarıda rakamlar üzerinde yapılan tartışmaların asıl kaynağı uzman görüşlerine göre belirlenen ağırlıklardır. $\mathrm{Bu}$ çalışmada futbola motorik beceriler açısından en yetenekli sporcuların siralaması alanda uzman kişiler tarafından şekillenmiştir. Ancak dönem dönem yapılan genel yetenek taramaları verileri farklı branșlardaki uzman kișiler tarafindan belirlenen ağırlıklara göre formülize edildiği takdirde genel yetenek taraması sonuçlarına göre her birey motorik becerileri en yatkın olduğu branşa kolayca yönlendirilebilir.

Alanda çoklu karar verme yöntemleri kullanılarak yapılan çalışmalar incelendiğinde antrpometrik özelliklerin ve futbola özgü beceri testlerinin de dahil edildiği ya da daha yüksek yaş gruplarına yönelik araştırmalar yapıldığı görülmüştür. Çalışmamız, kriterlerin nitel yöntemler kullanılarak ağırlıklandırılması sebebiyle bu çalışmalardan farklıl1k göstermektedir. Öyle ki, Qader ve arkadaşlarının yaptığı çalışmada (2017) 15-17 yaş arası sporculara antropometrik, motorik ve beceri testlerine yönelik bir değerlendirme yapılmış ve sporcular 4 grupta incelenmiştir. Kasap ve Kasap'ın (2005) yaptığı çalışmada ise A takım seviyesinde müsabakalar video aracılığg ile incelenmiş ve futbolcuların performanslarının değerlendirilebileceği bir veritabanı oluşturmuştur. Arnason ve arkadaşları (2004) ise çalışmamıza benzer kriterlerin takım başarısı arasındaki ilişkiyi incelemiştir.

Çalışmamızın sonucu olarak uyguladığımız yöntem, yetenek seçimi konusunda uygulanabilir bir alternatif olarak literatüre katk1 sağlayacağ1 düşüncesindeyiz. Özellikle belirtmek gerekir ki, çalışmamızdaki testlerin sonuçlarından ziyade yetenek taraması amacıyla yapılan ölçümlerin nitel verilerle desteklenerek sonuçlandırılması gerektiği vurgulanmalıdır. Literatürde nitel yöntemle desteklenen ve aynı zamanda AHP ve TOPSIS ile yetenek seçimi konusunda herhangi bir çalışmaya rastlanmadığından ikili karş1laştırma yöntemi ile oluşturulan kriter ağırlıkları bundan sonra yapılacak çalışmalar için örnek teşkil edecektir. Aynı zamanda futbol branşı için hesaplanan alana özgü ağırlıkların haricinde, diğer branşlara yönelik ağırlıkların hesaplanması yetenek seçiminde alternatif oluşturmuş olacak ve kolaylık sağlayacaktır.

\section{KAYNAKÇA}

Achillas, C., Moussiopoulos, N., Karagiannidis, A., Banias, G. ve Perkoulidis, G. (2013). The use of multi-criteria decision analysis to tackle waste management problems: a literature review, Waste Management \& Research, 31(2), ss. 115-129.

Aktuğ, Z., Rüçhan, i., \& Çelenk, Ç. (2019). Çocuklarda Motor Beceri İle Futbola Özgü Teknik Beceriler Arasındaki İlişkinin İncelenmesi. Spor ve Performans Araştırmaları Dergisi, 10(1), 13-23.

Arnason, S.B. Sigurdsson, A. Gudmundsson, I. Holme, L. Engebretsen, R. Bahr. (2004). Physical fitness, injuries, and team performance in soccer. Med. Sci. Sports Exerc. Feb;36 (2): 278-85.

Ayan, V., \& Mülazimoğlu, O. (2009). Sporda yetenek seçimi ve spora yönlendirmede 8-10 yaş grubu erkek çocuklarının fiziksel özelliklerinin ve bazı performans profillerinin incelenmesi (Ankara Örneği). FÜ Săg. Bil. Tıp Dergisi, 23(3), 113-118.

Chen, C.T. (2000). Extensions of the TOPSIS for Group Decision Making Under Fuzzy 
Environment, Fuzzy Sets and Systems, 114, ss. 1-9.

Chen, C.-F. (2006). Applying the analytical hierarchy process (AHP) approach to convention site selection. Journal of Travel Research, 45(2), 167-174.

Coombs, C.H.A. (1964). Theory of Data, UK: John Wiley and Sons

Cristóbal, J.R.S. (2012). Contractor Selection Using Multicriteria DecisionMaking Methods, Journal Of Construction Engineering and Management, 138(6), ss. 751-758.

Forman, E. H., \& Gass, S. I. (2001). The analytic hierarchy process - an exposition. Operations Research, 49(4), 469-486.

Forman, E. H ve Selly, M. A. (2001), Decision By Objectives (How To Convince Others That You Are Right), World Scientific Pub. Co., ABD.

Harker, P. ve Vargas, L. (1987). The Theory of Ratio Scale Estimation: Saaty's Analytic Hierarchy Process, Management Science, 33(11), ss. 1383-1403.

Ho, W., Xu, X. ve Dey, P.K. (2010) Multi-Criteria Decision Making Approaches for Supplier Evaluation and Selection: A Literature Review, European Journal of Operational Research, 202(1), ss. 16-24.

Hwang, C.L. ve Yoon, K. (1981). Multi Attiribute Decision Making Methods and Applications, Springer-Verlag.

Gil, S. M., Zabala-Lili, J., BidaurrazagaLetona, I., Aduna, B., Lekue, J. A., Santos-Concejero, J., \& Granados, C. (2014). Talent identification and selection process of outfield players and goalkeepers in a professional soccer club. Journal of Sports Sciences, 32(20), 1931-1939.
Güçlüöver, A., Şahin, İ. N., Mehmet, G., \& Esen, H. T. (2019) Sporda Yetenek Seçimi ve Spora Yönlendirmede 9-10 Yaş Çocukların Bazı Fiziksel Özellikleri ve Performans Profillerinin İncelenmesi: Kırıkkale Örneği. Gaziantep Üniversitesi Spor Bilimleri Dergisi, 4(2), 199-210.

Holtey, J., \& Özer, M. K. (2019). Sporda Yetenek Gelişimi ve Ötesi. Journal of Health and Sport Sciences, 2(2), 40-55.

Howe, M. J., Davidson, J. W., \& Sloboda, J. A. (1998). Innate talents: Reality or myth? Behavioral and brain sciences, 21(3), 399407.

Jabri, M. M. (1990). Personnel selection using INSIGHT-C: An application based on the analytic hierarchy process. Journal of Business and Psychology, 5(2), 281-285.

Karaatlı, M., Ömürbek, N., Köse, G. (2014). Analitik Hiyerarşi Süreci Temelli Topsis Ve Vikor Yöntemleri İle Futbolcu Performanslarinin

Değerlendirilmesi. Dokuz Eylül Üniversitesi İktisadi İdari Bilimler Fakültesi Dergisi, 29(1), 25-61.

Kasap, S., Kasap, N. (2005) Development of a database and decision support system for performance evaluation of soccer players. In: 35th International Conference on Computers and Industrial Engineering, Istanbul, Turkey.

Kousalya, P. Ravindranath, V. ve Vzayakumar, K. (2006). Student Absenteeism in Engineering Colleges: Evaluation on Alternatives Using AHP", Journal of Applied Mathematics and Decision Sciences, ss. 1-26.

Köktaş, E. (2013). Beden kütle indeksleri spor yapmaya uygun çocukların tenis branşına göre yetenek düzeylerinin 
Esen, S., Uslu, T. / Futbolda Yetenek Seçiminin Analitik Hiyerarşi Süreci ve TOPSIS Yöntemi Aracılığıyla Değerlendirilmesi

$\begin{array}{lrr}\text { araştırılması. } & \text { Selçuk } \\ \text { Üniversitesi } & \text { Sağlık } & \text { Bilimleri } \\ \text { Enstitüsü. } & & \end{array}$

Kurban, M. (2008). Futbol antrenmanının 10-13 yaş grubu çocukların teknik gelişimlerine etkisinin araştırılması. Selçuk Üniversitesi Sağlık Bilimleri Enstitüsü.

Lai, Y. J., Liu, T. Y. ve Hwang, C.L. (1994). TOPSIS for MODM, European Journal of Operational Research, 76(3), ss. 486-500.

Lin, M.C., Wang, C.C., Chen, M.S. ve Alec Chang, C., (2008). Using AHP and TOPSIS approaches in customer-driven product design process, Computers in Industry, 59, ss. 17-31.

Lin, Q., Li, D.D. ve Yang, Y.B. (2013). VIKOR Method with Enhanced Accuracy for Multiple Criteria Decision Making in Healthcare Management, Journal Of Medical Systems, 37(1).

Mengütay, S. (1999). Okul öncesi ve ilkokullarda hareket gelişimi ve spor: TUTİBAY.

Monjezi, M., Dehghani, H., Singh, T. N., Sayadi, A.R. ve Gholinejad, A. (2010). Application of TOPSIS Method for Selecting the Most Appropriate Blast Design, Arabian Journal of Geosciences, 5(1), ss. 95-101.

Opricovic, S. ve Tzeng, G.H. (2004). Compromise solution by MCDM methods: A comparative analysis of VIKOR and TOPSIS, European Journal of Operational Research, 156, ss. 445-455.

Qader, M. A., Zaidan, B. B., Zaidan, A. A., Ali, S. K., Kamaluddin, M. A., Radzi, W. B. (2017). A methodology for football players selection problem based on multi-measurements criteria analysis. Measurement, Volume 111, December 2017, Pages 38-50.
Saaty, T. L. (1994). How to Make a Decision - the Analytic Hierarchy Process. Interfaces, 24(6), 19-43.

Saaty, T.L. (2008). Decision Making with the Analytic Hierarchy Process, International Journal of Services Sciences, 1(1), ss. 83-98.

Sathya, S. S., \& Jamal, M. S. Applying genetic algorithm to select an optimal cricket team. Paper presented at the Proceedings of the International Conference on Advances in Computing, Communication and Control, ICAC3. (2009).

Shyjith, K., Ilangkumaran, M. ve Kumanan, S. (2008). Multicriteria decision-making approach to evaluate optimum maintenance strategy in textile industry, Journal of Quality in Maintenance Engineering, 14(4), ss. 375-386

Timor, M. (2011). Analitik Hiyerarşi Prosesi, Türkmen Kitabevi, İstanbul.

Tsaur, S.H., Chang, T.Y. \& Yen, C.H., (2002). The Evaluation of Airline Service Quality by Fuzzy MCDM, Tourism Management, 23, ss. 107-115.

Tutkun, E., Eyuboğlu, E., \& Ağaoğlu, S. (2006). İlköğretim çağ1 çocuklarında antropometrik ölçümlerle bazı fiziksel ve fizyolojik parametrelerin ilişkisi. 9. Uluslararası Spor Bilimleri Kongresi Bildiri Kitab1, s, 529-531.

Ünal, Ö. F. (2011). Analitik Hiyerarşi Prosesi ve Personel Seçimi Alaninda Uygulamalari. Journal Of Alanya Faculty Of Business/Alanya İsletme Fakültesi Dergisi, 3(2).

Vaeyens, R., Lenoir, M., Williams, A. M., \& Philippaerts, R. M. (2008). Talent identification and development programmes in sport - Current models and future directions. Sports Medicine, 38(9), 703-714. 
Wei, J. (2010). TOPSIS Method for Multiple Attribute Decision Making with Incomplete Weight Information in Linguistic Setting, Journal of Convergence Information Technology, 5(10), ss. 181187.

Wind, Y ve Saaty, T.L. (1980). Marketing Application of the Analytic Hierarchy Process, Management Science, 26(7), ss. 641-658.

Yıldırım, B. F., \& Önder, E. (2015). Çok kriterli karar verme yöntemleri. Bursa: Dora Basım-Yayın Dağıtım.

Yoon, K. (1987). A Reconciliation Among Discrete Compromise Solutions, Journal of Operational Research Society, 38(3), ss. 272-286. 